\title{
Dyslexic students have more everyday cognitive lapses.
}

\author{
James H. Smith-Spark, \\ Department of Psychology, Keynes College, University of Kent at Canterbury, Canterbury, \\ CT2 7NP, UK, \\ Angela J. Fawcett, Roderick I. Nicolson, \\ Department of Psychology, University of Sheffield, Western Bank, Sheffield, S10 2TN, \\ UK, \\ $\&$ \\ John E. Fisk, \\ School of Psychology, Liverpool John Moores University, 15-21 Webster Street, Liverpool, \\ L3 2ET, UK.
}

Short title.

Dyslexia and Everyday Memory.

\section{Corresponding Author.}

Dr. James Smith-Spark, Department of Psychology, Keynes College, University of Kent at Canterbury, Canterbury, CT2 7NP, UK.

E-mail: j.h.smith-spark@ukc.ac.uk

Tel. 01227824107.

Fax 01227827030. 


\section{Acknowledgements.}

This research was supported by a Medical Research Council PhD Studentship awarded to the first author. We are grateful to Professor Alan Baddeley, Dr. Jackie Andrade, and two anonymous reviewers for comments made on earlier versions of this work. 


\begin{abstract}
.
There is a dearth of information about everyday performance difficulties of adult dyslexic people. This study investigates the empirical support for anecdotal reports of increased vulnerability to distraction in dyslexia, using the self-report Cognitive Failures Questionnaire (CFQ). Two groups of university students, a dyslexic group and a nondyslexic control group, were asked to complete the CFQ. The dyslexic group reported a higher frequency of everyday lapses in cognition, scoring significantly higher on a number of CFQ items. Representative problems include distractibility, over-focusing (so that relevant peripheral information is missed), and word-finding difficulties. A similar measure administered to close friends of dyslexic people, the CFQ-for-others, yielded results consistent with those of the CFQ, with major findings being that their friends considered them to be more disorganised, more distractible, and more absent-minded than normal. The results indicate clearly the continuing effects of dyslexia on cognition in adulthood and demonstrate that dyslexic impairments are not limited to "artificial" laboratory tasks or even literacy tasks but, instead, pervade everyday life.
\end{abstract}

\title{
Keywords.
}

Dyslexia, adults, everyday slips, memory, organisation 


\section{Introduction.}

Developmental dyslexia is a condition that affects some 5\% of people in Englishspeaking countries (Badian, 1984). There is a strong genetic link (e.g. Gayan \& Olson, 1999) and so children do not 'grow out of' dyslexia. The phonological deficit hypothesis (Bradley \& Bryant, 1983; Snowling, 1987; Stanovich, 1988) was the dominant theory of dyslexia in the last twenty years and, as a result, has had a major influence on research. The hypothesis asserts that an impairment in phonological processing is responsible for most, if not all, of the reading and spelling difficulties associated with dyslexia. In addition to problems in the phonological skill, however, deficits have been reported in other domains. For example, Wolf and Bowers (1999) have integrated a number of findings to propose the 'double deficit' hypothesis, which posits that dyslexic children have core deficits not only in phonological skills but also in speed of processing. As a result, while the impairments associated with the condition are well documented, there is still debate as to the underlying causes of dyslexia.

Laboratory studies are critically important in attempting to investigate this issue, but it is possible that more 'ecologically valid' studies of real-world performance will provide complementary information that help to build a more complete picture of the everyday problems of dyslexic people, and will therefore be of value in developing applied support environments. It is also possible that the ecologically valid analyses will yield theoretical insights that are not apparent from the constrained conditions of the laboratory (cf. Neisser, 1978, although see Banaji \& Crowder, 1994 for a dissenting view). 
Since dyslexia is at least partly genetic (see Fisher \& Smith, 2001, for a review), there will be a similar prevalence of dyslexia in adults as in children. The demand for selfappraisal and, more obviously, the need to order one's own life in adulthood makes it salient that such everyday investigations will be suited better to adult populations. Moreover, McLoughlin, Fitzgibbon and Young (1994) argue that it is important to treat adult dyslexics as a population distinct from childhood dyslexics, in that they have different problems and requirements. They argue that "adult dyslexics are not simply children with a learning disability "grown up"” (p. 1) and that problems remain even when reading is remediated. This perspective means that a broader view of dyslexia must be taken than one that concentrates solely on the reading, writing, and spelling deficits concomitant with the disorder (e.g. Frith, 1985; Snowling, Goulandris, Bowlby \& Howell, 1986; Stanovich, 1988). Thus, it is important to perform detailed studies on cognitive function in adult dyslexics. Consequently, this study focuses on the everyday memory performance of just such an experimental group.

Despite the importance of such work to both dyslexia theory and educational and support services, little empirical work has been published that examines the everyday cognition of dyslexics in either childhood or adulthood. Since the UK Disability Discrimination Act 1995 (c.50) requires employers to make suitable accommodations to help dyslexic adults cope with their working environments, it is crucial to attempt to characterise the problems they are likely to face.

A crucial aspect of everyday memory is prospective remembering, the ability to remember to do a certain thing at a certain time. McDaniel and Einstein (2000) have proposed a multi-process framework for prospective memory recall, with a number of 
central cognitive processes being involved in prospective remembering. These processes include one in which an executive attentional system (such as the Supervisory Attentional System of Norman \& Shallice, 1986) monitors the environment for markers of the intended action and/or brings the action to mind periodically, thereby maintaining the activation level of the association between the cue and the action. Relatively resource free and spontaneous automatic processes to cue remembering are also possible within this model. Kliegel, Martin, McDaniel and Einstein (2001) consider the allocation of attention away from an ongoing task to a prospective task to be selective (especially when the time of the prospective memory event can be anticipated), rather than being a general drain on attentional resources. It has also been proposed that an $\mathrm{ACT}^{*}$ (Anderson, 1983) production rule can be used to explain aspects of event-based (when a cue in the environment causes memory for the action to be activated) prospective memory (Marsh, Hicks \& Hancock, 2000). Ongoing activities that require more executive processes and thus, more attentional resources, reduce the efficacy of event-based prospective memory (Marsh \& Hicks, 1998). Given the reports of dyslexic problems with automatisation and attention (e.g. Nicolson \& Fawcett, 1990), it is likely that such impairments will manifest themselves in naturalistic prospective memory settings. Nicolson and Fawcett's Dyslexic Automatisation Deficit hypothesis predicts that deficits would become apparent in dyslexic performance when heavy cognitive/ attentional demands are made upon the system, with factors such as tiredness and stress predicted to affect the dyslexic group more than the controls.

Some evidence for everyday memory problems in dyslexia is extant in the literature (e.g. Turner, 1997). McLoughlin, Fitzgibbon and Young (1994) provide extensive evidence that factors such as reduced working memory have wide-ranging effects in many situations. 
More specific impairments of everyday memory in dyslexia have also been reported. For example, Miles (1982) argues that temporal sequencing problems associated with dyslexia extend to everyday life, for example in ordering one's life, telling the time, and remembering days of the week and months of the year. Temporal processing difficulties have been found also by Tallal (1985). There have been reports of increased forgetfulness and clumsiness in dyslexics (e.g. Miles, 1982; Augur, 1985; McLoughlin, Fitzgibbon \& Young, 1994). Experimental evidence on motor skill and dyslexia presented by Fawcett and Nicolson (1995) has supported such reports. Although many motor decrements have disappeared by late adolescence, older dyslexics have problems with sequencing (e.g. Wolff, Michel, Ovrut \& Drake, 1990) and with planning (Torgeson, 1977; Levin, 1990). Impairments with planning will obviously impinge upon academic life. For example, Gilroy and Miles (1996) report that dyslexic students have problems in essay writing as a result of planning and structuring difficulties. An increased propensity to daydreaming in dyslexia has also been reported (Augur, 1985).

One potential source of variance in everyday cognition is provided by the frequency with which plans go awry or actions are performed not as intended. These "slips of action" (Reason, 1979) form one subcategory of such cognitive failure, the focus of this study. In order to gain a more quantitative assessment of the relative frequency of such errors in dyslexics and non-dyslexics, a self-report measure was administered. The Cognitive Failures Questionnaire (CFQ) of Broadbent, Cooper, FitzGerald and Parkes (1982) is a twenty-five item self-report measure that is designed to probe the incidence and pattern of cognitive failure in everyday life. It has been used extensively in the psychological literature, being employed recently, for example, to examine everyday cognition in the 
elderly (Klumb, 2001), in recreational users of "ecstasy" (Rodgers, 2001), and in psychiatric contexts (Wagle, Berrios \& Ho, 1999). The CFQ assesses a number of different types of error in ongoing cognition, such as slips of memory, language, and attention. Under laboratory conditions, dyslexic impairments have been reported in all three of these constructs (e.g. Vellutino, 1979; Bradley \& Bryant, 1983; Jorm, 1983; Nicolson \& Fawcett, 1990). Therefore, if laboratory studies do measure non-trivial processes, then the responses of an individual with dyslexia would be expected to be significantly different from those of a non-dyslexic, with a higher incidence of cognitive failures being expected in dyslexia.

Cohen (1996) argues that self-report questionnaires are assessed better by gaining an independent measure of everyday performance, such as that provided by ratings by a third party. In the present study, this concern is addressed by the CFQ-for-others, a questionnaire to be completed by individuals who have a significant relationship with the CFQ respondent, such as family members or partners. The CFQ-for-others provides a means of determining whether the self-reports of CFQ respondents are idiosyncratic or whether their beliefs about their own cognitive failures are generally accurate. Broadbent et al. (1982) found there to be a good correlation between the judgements of CFQ respondents concerning cognitive failures and those of the CFQ-for-others respondents. The correlation suggests that individuals who report more cognitive failures do in fact produce more such errors. However, everyday memory failures such as those identified by Vinegrad's (1994) Adult Dyslexia Check List may be due to lowered self-concepts in dyslexia (cf. Riddick, Sterling, Farmer \& Morgan, 1999). Self-esteem problems in adult dyslexia are most apparent in high-literacy settings (Gerber, Schneiders, Paradise, Reiff, Ginsborg \& Popp, 1990). Since the participants employed in the present study are all university students, the 
CFQ-for-others should permit an important estimation of the extent to which self-concepts play a part in rating cognitive failures.

The results of the CFQ-for-others should be consistent with the CFQ in terms of group differences in overall scores, if the case for an increased susceptibility to everyday cognitive error in dyslexia is to be upheld. In particular, there should be a higher rating of disorganisation, clumsiness and absent-mindedness by those respondents who have day-today contact with the dyslexic participants.

\section{Method.}

\section{Participants.}

The participants consisted of two groups of university students. The dyslexic group consisted of 26 individuals ( 8 females, 18 males) and were all diagnosed within the Department of Psychology at The University of Sheffield, using Nicolson and Fawcett's (1997) Adult Dyslexia Diagnostic Test. This adult dyslexia diagnosis tool provides an Adult Dyslexia Index (ADI) score for an individual, obtained from performance on four positive indicators of dyslexia. These are the full WAIS-R (Wechsler, 1986a), WORD spelling (Wechsler Objective Reading Dimensions; Wechsler, 1986b), speed and accuracy of reading a nonsense passage known to identify deficits even in compensated dyslexics (Finucci, Guthrie, Childs, Abbey \& Childs, 1976; Brachacki, Fawcett \& Nicolson, 1994), and a previous diagnosis of dyslexia. Performance on each of the four indicators provides a score of $0,0.5$, or 1 . The method of determining the cut-off scores on each of the indicators is described in depth by Nicolson and Fawcett (1997). Composite scores on the tests 
provide an ADI score ranging between 0 (non-dyslexic) to 4 (dyslexic). Scores of 3 or more provide strong evidence for dyslexia, 2.5 represents good evidence for the condition, scores of 1.5 to 2 are taken as cases of "borderline" dyslexia, whilst 1 and below are interpreted as providing no evidence of dyslexia. In the present study, the dyslexic group had a mean ADI score of $2.90(\mathrm{SD}=0.75)$, a good indication of dyslexia, and a mean IQ of $111.08(\mathrm{SD}=$ 10.90).

The control group comprised 22 non-dyslexics (10 females, 12 males). All controls reported no problems with literacy and this was supported by their writing and spelling on the written components of these and other tests that were administered to them (SmithSpark, 2000). Self-reports of being non-dyslexic have been found to be accurate by Nicolson and Fawcett (1997) in a study of 150 students, none of whom showed any evidence of dyslexia ${ }^{1}$.

The average age of the two groups was 24.53 years $(\mathrm{SD}=5.26)$ for the dyslexic group and 20.78 years $(\mathrm{SD}=1.57)$ for the control group. The average number of years spent in education was 15.20 years $(\mathrm{SD}=1.78)$ for the dyslexic group and 15.41 years $(\mathrm{SD}=1.44)$ in the case of the control group.

\section{Design.}

The Cognitive Failures Questionnaire (CFQ) of Broadbent et al. (1982) was administered to two groups of participants, one consisting of dyslexic adult students and the other a control group of non-dyslexic students. The 25-item CFQ is argued to measure the relationship between attentional performance and general cognitive functioning. The questions relate to different aspects of cognitive functioning and failure, such as perceptual failures, 
misdirected actions, and memory failures. The term "cognitive failure" is used as an umbrella term for all three types of slip.

The CFQ-for-others is designed to gain an independent view of the participant's behaviour, tapping the day-to-day experience of a significant other. In the original study Broadbent et al. use family or partners of the participant but due to the nature of student populations, the present study "housemate" has been added to this list of significant others.

Bonferroni corrections were performed on the individual analyses of the items of the CFQ and CFQ-for-others in order to counter an inflated Type I error caused by multiple comparisons. The $\mathrm{p}$-value for items on the CFQ had to be less than 0.002 and 0.005 for the CFQ-for-others to reach statistical significance at the .05 level.

\section{Materials.}

The Cognitive Failures Questionnaire (CFQ) and CFQ-for-others (Broadbent et al., 1982) were administered. Each questionnaire item required a number (0-4 inclusive) to be circled. 4 corresponded to "Very Often" and 0 to "Never". The direction of scoring for the CFQ was unidirectional, since pilot studies by Broadbent et al. (1982) found that reversed wording on some items only confused the participants and there were no differences in a small sample using reversed wording. In the case of the CFQ-for-others, half of the items began with "Very Often" and half with "Never".

\section{Procedure.}

The Cognitive Failures Questionnaire (CFQ). The instructions were the same as those employed by Broadbent et al. (1982), again asking the respondent to consider 
mistakes made by the CFQ respondent in the previous six months. The questions used in the CFQ are to be found in the Results section. Participants were allowed as long as they needed to complete the questionnaire.

The CFQ-for-others. After completing the CFQ, participants were given the CFQ-for-others and asked to get someone that had day-to-day experience with them (i.e. a family member, partner, or housemate) to fill it in. The CFQ respondent was requested not to discuss the responses that he or she had made prior to the completion of the CFQ-for-others. The same set of instructions as Broadbent et al. (1982) employed, again asking the respondent to consider mistakes made by the CFQ respondent in the previous six months.

The CFQ-for-others respondents were requested to complete the questionnaire and return it to the experimenter in a pre-paid envelope. Again, the questions can be found in the Results section.

\section{Results.}

\section{The CFQ.}

An independent groups t-test carried out on overall CFQ score revealed a significant difference between the groups, $\underline{\mathrm{t}}(46)=-4.952, \underline{\mathrm{P}}<0.001$, with the dyslexics reporting significantly higher frequencies of slips $($ mean $=61.25, \mathrm{SD}=10.32)$ than the controls $($ mean $=47.75, \mathrm{SD}=8.21)$. The mean difference between the groups was thus 13.50.

The mean self-ratings of both groups on each item of the CFQ, together with univariate F-test results with $(1,43)$ D.F., are given in Table 1. Significant differences 
between the two groups were found on fifteen of the twenty-five items of the questionnaire. In each case, the members of the dyslexic group rated themselves as producing slips of the type probed by that particular CFQ item more frequently than the control participants. Bonferroni corrections were applied to the data, after which significant differences remained on six questionnaire items (namely, Items 2, 7, 9, 14, 22, and 23). Pollina, Greene, Tunick and Puckett (1992) carried out a principal components analysis on CFQ data collected from 387 college students. Table 1 shows how the data from the present study fit the factors extracted from this large-scale study. It can be seen that the items on which the significant group differences emerged are spread across the five factors reported by Pollina et al.; namely distractibility, misdirected actions, spatial/kinaesthetic memory, memory for names, and interpersonal intelligence.

\section{TABLE 1 ABOUT HERE.}

On no item did the controls rate the frequency with which they produced cognitive failures significantly higher than the dyslexic group. Indeed, their mean ratings were higher on only three items, "15. Do you have trouble making up your mind?", "24. Do you drop things?”, and “25. Do you find you can’t think of anything to say?”.

\section{The CFQ--for-others.}

The ratings for each question were added together to give a total CFQ-for-others score for each individual. This ranged from a minimum score of 0 to a maximum of 32. Respondents rated the cognitive failures of the dyslexic group (mean $=16.60, \mathrm{SD}=6.85)$ as being more frequent than those of the non-dyslexics $($ mean $=13.29, \mathrm{SD}=3.24), \underline{\mathrm{t}}(44)=-2.03, \underline{\mathrm{P}}<$ 0.05. There was, therefore, a mean difference of 3.31 between the groups. 
Group mean ratings for the individual items of the CFQ-for-others are given in Table 2, together with univariate F-test results. The dyslexics were differentiated from the controls on three of the eight items of the CFQ-for-others. After Bonferroni corrections were applied to the analyses, differences on two of the items remained significant (" 1 . Absent-minded, that is making mistakes in what he/she is doing because he/she is thinking of something else?" and "7. Disorganised, that is, getting into a muddle when doing something because of lack of planning or concentration?").

\section{TABLE 2 ABOUT HERE.}

Overall scores on the CFQ and CFQ-for-others yielded a significant one-tailed Pearson's correlation between the two measures, $\mathrm{r}=0.43, \underline{\mathrm{P}}=0.003$.

\section{Discussion.}

It can be seen that a number of significant group-related differences emerged on the CFQ. These were found on the overall measure of self-reported frequency of slips of action and also on individual questionnaire items. Overall, the dyslexic group rated themselves as experiencing cognitive slips more often than the control group. Such differences were reflected also in the overall score on the CFQ-for-others. The CFQ was shown to have good internal reliability. When the more stringent Bonferroni corrections were applied, significant group differences remained on six items concerned with slips of attention, absentmindedness, language skills (such as selection of words), and planning. It is interesting to note that the dyslexic group view their problems with names to be the result of failing to encode them in the first place (Item 2), and less a problem of memory per se. In 
the light of previous work (e.g. Miles, 1982, 1983; Augur, 1985), it is surprising that no significant difference was found in the incidence of left and right confusions, although it should be noted that this result approached significance.

Consistent with studies in laboratory settings and also theories of prospective memory (e.g. Marsh \& Hicks, 1998; McDaniel \& Einstein, 2000), it would seem that many of the problems encountered by dyslexics in everyday life are to do with the allocation of attentional resources and memory. Indeed, Pollina et al. (1992) have argued from their own data on the CFQ that attention is an important factor in everyday memory. An attentional account of the everyday memory impairments reported in this paper also consistent with the DAD hypothesis of Nicolson and Fawcett (1990). More generally, these difficulties argue for a broader explanation of the condition than one that focuses specifically on language impairments (e.g. Vellutino, 1979; Stanovich, 1988). Thus, the dyslexic adult will still encounter difficulties in everyday life, even if he or she is not working in a setting that demands competence in literacy or academic skills.

The use of students as the sample population may lead to an increased sensitivity to memory performance and to more opportunities for memory failures to occur in day-to-day life (Cornish, 2000), since they will be reliant on their memory in examinations. This may lead to over-reporting of failures relative to the general population. Whilst this is of no real concern to the results of the present study, since both groups consisted entirely of students, it would be interesting to examine the performance of dyslexics and controls drawn from a wider sample base.

The results of the CFQ-for-others indicate that the two groups differed significantly from each other overall. The dyslexic group was rated as more prone to slips on three of the 
eight items of the questionnaire. When Bonferroni corrections were applied, significant differences remained on two of the CFQ-for-others items. On the basis of the ratings provided by individuals who had day-to-day contact with the participants, it would appear that the everyday impairments of the dyslexic group are centred on attention, absentmindedness, and organisation. In particular, their perceived significantly greater lack of organisational skills (Item 7) would appear to support the laboratory-based work of Torgesen (1977) and Levin (1990) who argue for planning deficits in dyslexia. Again, the increased vulnerability to distraction and lack of efficiency in planning, highlighted by both the CFQ and CFQ-for-others, would suggest some impairment in attentional or central executive mechanisms (e.g. Baddeley, 1986; Norman \& Shallice, 1986).

In summary, the results of the CFQ and CFQ-for-others indicate that dyslexic and control adults differ in the self-rating of the frequency of cognitive failures in day-to-day life. Overall, the dyslexics rate themselves as being more vulnerable to lapses. It would appear from the CFQ and CFQ-for-others that the group differences manifest themselves in terms of a greater proclivity to problems in distractibility, over-focusing (so that relevant peripheral information is missed- c.f. McDaniel \& Einstein, 2000; Marsh \& Hicks, 2000), memory, and word-finding difficulties. This is in accordance with both anecdotal reports and laboratory studies and presents a strong case for further work to investigate everyday cognition in dyslexia. In addition, it would appear that, despite their artificial nature, laboratory studies of dyslexia elicit impairments that reflect processes that are of significance to the individual in everyday life. 
The adoption of the everyday memory paradigm has provided new insight into the memory problems of dyslexia and has gone some way toward showing that phonological processes, whilst playing an important role in the condition, are not responsible for all the deficits apparent in this area of cognition. This study indicates that there is a broad range of everyday difficulties experienced by dyslexic adults. The problems associated with the condition are not restricted either to the laboratory setting, academic contexts, or to the phonological domain. It is vital that these difficulties are taken into account when designing working environments to support adults with dyslexia. 


\section{References.}

Anderson, J.R. (1983). The Architecture of Cognition. Cambridge, MA: Harvard University Press.

Augur, J. (1985). Guidelines for teachers, parents and learners. In M. Snowling (Ed.), Children's Written Language Difficulties (pp. 147-170). Windsor, Berkshire: NFER-Nelson.

Baddeley, A.D. (1986). Working Memory. Oxford: Clarendon Press.

Badian, N.A. (1984). Reading Disability as an epidemiological context: incidence and environmental correlates. Journal of Learning Disabilities, $\underline{17}, 129-136$.

Banaji, M.R., \& Crowder, R.G. (1994). Experimentation and its discontents. In P.E. Morris \& M. Gruneberg (Eds.), Theoretical Aspects of Memory (2nd ed., pp. 296306). London and New York: Routledge.

Brachacki, G.W.Z., Fawcett, A.J., \& Nicolson, R.I. (1994). Adults with dyslexia have a deficit in voice recognition. Perceptual and Motor Skills, 78 (1), 304-306.

Bradley, L., \& Bryant, P.E. (1983). Categorising sounds and learning to read- a causal connection. Nature, $\underline{301}, 419-421$.

Broadbent, D.E., Cooper, P.F., FitzGerald, P., \& Parkes, K.R. (1982). The Cognitive Failure Questionnaire (CFQ) and its correlates. British Journal of Clinical Psychology, 21, 1-16.

Cohen, G. (1996). Memory in the Real World (2nd ed.). Hove: Psychology Press.

Cornish, I.M. (2000). Factor structure of the Everyday Memory Questionnaire. British Journal of Psychology, 91, 427-438. 
Fawcett, A.J., \& Nicolson, R.I. (1995). Persistent deficits in motor skill of children with dyslexia. Journal of Motor Behaviour, 27(3), 235-240.

Fisher, S.E., \& Smith, S.D. (2001). Progress towards the identification of genes influencing developmental dyslexia. In Fawcett, A.J. (Ed.), Dyslexia: Theory and Good Practice (pp. 39-64). London: Whurr.

Finucci, J.M., Guthrie, J.T., Childs, A.L., Abbey, H., \& Childs, R. (1976). The genetics of specific reading disability. Annals of Human Genetics, 50, 1-23.

Frith, U. (1985). Beneath the surface of developmental dyslexia. In K.E. Patterson, J.C. Marshall \& M. Coltheart (Eds.), Surface Dyslexia. London: Routledge and Kegan Paul.

Gayan, J., \& Olson, R. K. (1999). Reading disability: Evidence for a genetic etiology. European Child \& Adolescent Psychiatry, $\underline{8}$, 52-55.

Gerber, P.J., Schneiders, C.A., Paradise, L.V., Reiff, H.B., Ginsborg, R.J., \& Popp, P.A. (1990). Persisting problems of adults with learning disabilities: self-reported comparisons from their school-age and adult years. Journal of Learning Disabilities, $\underline{29}, 439-446$.

Gilroy, D.E., \& Miles, T.R. (1996). Dyslexia at college (2nd ed.). London and New York: Routledge.

Jorm, A.F. (1983). Specific reading retardation and working memory: A review. British Journal of Psychology, 74, 311-342.

Kliegel, M., Martin, M., McDaniel, M.A., \& Einstein, G.O. (2001). Varying the importance of a prospective memory task: differential effects across time- and event-based prospective memory. Memory, 9(1), 1-11. 
Klumb, P.L. (2001). Tying knots in handkerchiefs: The use of memory aids in everyday life. Zeitschrift für Entwicklungspsychologie und Padagogische Psychologie, 33(1), 42-49.

Levin, B.E. (1990). Organisational Deficits in Dyslexia: Possible Frontal Lobe Dysfunction. Developmental Neuropsychology, 6(2), 95-110.

Marsh, R.L., \& Hicks, J.L. (1998). Event-based prospective memory and executive control of working memory. Journal of Experimental Psychology: Learning, Memory, and Cognition, 24(2), 336-349.

Marsh, R.L., Hicks, J.L., \& Hancock, T.W. (2000). On the interaction of ongoing cognitive activity and the nature of an event-based intention. Applied Cognitive Psychology, 14, S29-S41.

McDaniel, M.A, \& Einstein, G.O. (2000). Strategic and automatic processes in prospective memory retrieval: a multiprocess framework. Applied Cognitive Psychology, 14, S127-144.

McLoughlin, D., Fitzgibbon, G., \& Young, V. (1994). Adult Dyslexia: Assessment, Counselling and Training. London: Whurr.

Miles, T.R. (1982). The Bangor Dyslexia Test. Cambridge: Learning Development Aids.

Miles, T.R. (1983). Dyslexia: The Pattern of Difficulties. London: Priory Press.

Neisser, U. (1978). Memory: What are the important questions? In M.M Gruneberg, P.E. Morris \& R.N. Sykes (Eds.), Practical Aspects of Memory. London: Academic Press.

Nicolson, R.I., \& Fawcett, A.J. (1990). Automaticity: a new framework for dyslexia research. $\underline{\text { Cognition, }} \underline{35}, 159-182$. 
Nicolson, R.I., \& Fawcett, A.J. (1997). Development of objective procedures for screening and assessment of dyslexic students in higher education. Journal of

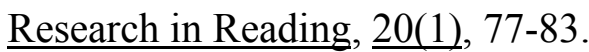

Norman, D.A., \& Shallice, T. (1986). Attention to Action: Willed and Automatic Control of Behaviour. In R.J. Davidson, G.E. Schwartz, \& D. Shapiro (Eds.), Consciousness and Self-Regulation: Advances in Research and Theory (Vol.4, pp. 1-18). New York: Plenum Press.

Pollina, L.K., Greene, A.L., Tunick, R.H., \& Puckett, J.M. (1992). Dimensions of everyday

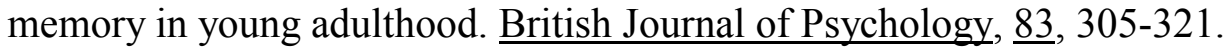

Reason, J. (1979). Actions not as planned: The price of automatization. In G. Underwood \& R. Stevens (Eds.), Aspects of Consciousness (Vol. 1: Psychological Issues, pp. 67-89). London: Academic Press.

Riddick, B., Sterling, C., Farmer, M., \& Morgan, S. (1999). Self-esteem and anxiety in the educational histories of adult student dyslexics. Dyslexia, $\underline{5}, 227-248$.

Rodgers, J. (2001). Cognitive performance amongst recreational users of "ecstasy". Psychopharmacology, 151 (1), 19-24.

Smith-Spark, J.H. (2000). Memory in Adult Dyslexics: An Exploration of the Working Memory System. Unpublished PhD thesis, University of Sheffield, UK.

Snowling, M.J., Goulandris, N., Bowlby, M., \& Howell, P. (1986). Segmentation and speech perception in relation to reading skill: A developmental analysis. Journal of Experimental Child Psychology, 41, 489-507.

Snowling, M. (1987). Dyslexia: A cognitive developmental perspective. Oxford: Blackwell. 
Stanovich, K. E. (1988). Explaining the differences between the dyslexic and the gardenvariety poor reader: The phonological-core variable-difference model. Journal of Learning Disabilities, 21, 590-612.

Tallal, P. (1985). Auditory temporal perception, phonics and reading disabilities in children. Brain \& Language, $\underline{9}, 182-198$.

Torgesen, J.K. (1977). The role of nonspecific factors in the task performance of learning disabled children: A theoretical assessment. Child Development, $\underline{48}, 56-60$.

Turner, M. (1997). Psychological Assessment of Dyslexia. London: Whurr.

Vellutino, F.R. (1979). Dyslexia: Theory and Research. Cambridge, MA: MIT Press.

Vinegrad, M. (1994). A revised adult dyslexia check list. Educare, $\underline{48}, 21-23$.

Wagle, A.C., Berrios, G.E., \& Ho, L. (1999). The cognitive failures questionnaire in psychiatry. Comprehensive Psychiatry, 40(6), 478-484.

Wechsler, D. (1986a). The Wechsler Adult Intelligence Scale- Revised (UK Edition). Sidcup, Kent: The Psychological Corporation.

Wechsler, D. (1986b). The Wechsler Objective Reading Dimensions. Sidcup, Kent: The Psychological Corporation.

Wolf, M., \& Bowers, P. G. (1999). The double-deficit hypothesis for the developmental dyslexias. Journal of Educational Psychology, 91, 415-438.

Wolff, P.H., Michel, G.F., Ovrut, M., \& Drake, C. (1990). Rate and timing precision of motor coordination in developmental dyslexia. Developmental Psychology, 26, 344359. 
Table 1: Group means and F-values for each item of the CFQ. Self-ratings of the frequency of occurrence of the CFQ items ranged from 0 (Never) to 4 (Very Often). Significance levels are indicated prior to application of Bonferroni corrections. For corrected significance at the $\underline{\mathrm{P}}<0.05$ level, items must have a P-value of less than $\mathbf{0 . 0 0 2}$. The final column fits the data of the present study to the five factors extracted from Pollina et al.'s (1992) principal components analysis.

\begin{tabular}{|c|c|c|c|c|c|}
\hline CFQ Item & Control & Dyslexic & $\mathbf{F}$ & $\mathbf{P}$ & Factor \\
\hline $\begin{array}{l}\text { 1. Do you read something and } \\
\text { find you haven't been thinking } \\
\text { about it and must read it again? }\end{array}$ & 2.94 & 3.38 & 2.69 & .109 & Distractibility \\
\hline $\begin{array}{l}\text { 2. Do you find you forget why } \\
\text { you went from one part of the } \\
\text { house to the other? }\end{array}$ & 1.84 & 2.62 & 11.59 & $.001 * *$ & Distractibility \\
\hline $\begin{array}{l}\text { 3. Do you fail to notice signposts } \\
\text { on the road? }\end{array}$ & 1.53 & 2.16 & 4.27 & $.045 *$ & $\begin{array}{l}\text { Spatial/ } \\
\text { kinaesthetic } \\
\text { memory }\end{array}$ \\
\hline $\begin{array}{l}\text { 4. Do you find that you confuse } \\
\text { right and left when giving } \\
\text { directions? }\end{array}$ & 1.40 & 2.14 & 3.33 & .075 & $\begin{array}{l}\text { Spatial/ } \\
\text { kinaesthetic } \\
\text { memory }\end{array}$ \\
\hline 5. Do you bump into people? & 1.53 & 1.64 & 0.15 & .697 & $\begin{array}{l}\text { Spatial/ } \\
\text { kinaesthetic } \\
\text { memory }\end{array}$ \\
\hline $\begin{array}{l}\text { 6. Do you find that you forget } \\
\text { whether you've turned off a light } \\
\text { or fire or locked the door? }\end{array}$ & 1.82 & 2.60 & 7.72 & $.008 * *$ & $\begin{array}{c}\text { Spatial/ } \\
\text { kinaesthetic } \\
\text { memory }\end{array}$ \\
\hline $\begin{array}{l}\text { 7. Do you fail to listen to people's } \\
\text { names when you are meeting } \\
\text { them? }\end{array}$ & 2.61 & 3.46 & 13.38 & $.001 * *$ & $\begin{array}{c}\text { Memory for } \\
\text { names }\end{array}$ \\
\hline $\begin{array}{l}\text { 8. Do you find that you say } \\
\text { something and realise that it } \\
\text { might be taken as insulting? }\end{array}$ & 1.76 & 2.28 & 4.71 & $.036^{*}$ & $\begin{array}{l}\text { Interpersonal } \\
\text { intelligence }\end{array}$ \\
\hline $\begin{array}{l}\text { 9. Do you fail to hear people } \\
\text { speaking to you when you are } \\
\text { doing something else? }\end{array}$ & 1.82 & 2.74 & 12.04 & $.001 * *$ & $\begin{array}{l}\text { Misdirected } \\
\text { actions }\end{array}$ \\
\hline 10. Do you lose your temper and & 0.95 & 1.80 & 8.46 & $.006 * *$ & Interpersonal \\
\hline
\end{tabular}


regret it?

11. Do you leave important letters

1.90

2.76

6.61

intelligence

unanswered for days?

12. Do you find you forget which

1.16

1.64

3.03

$.014 *$

Interpersonal

way to turn on a road you know

well but rarely use?

13. Do you fail to see what you

want in a supermarket (although

it's there)?

14. Do you find yourself suddenly

1.79

2.52

5.92

.089

intelligence

wondering whether you've used a

word correctly?

15. Do you have trouble making

2.26

2.12

0.19

Misdirected

actions

up your mind?

16. Do you find you forget

1.32

1.84

3.37

.073

2.29

2.92

6.55

$.014 *$

17. Do you forget where you put

something like a newspaper?

18. Do you find you accidentally

1.53

1.78

0.73

.397

throw away the thing you want

and keep what you meant to

throw away- as in the example of

throwing away the matchbox and

putting the used match in your

pocket?

19. Do you daydream when you

ought to be listening to

something?

20. Do you forget people's

2.84

3.36

3.89

.055

$.004 * *$

Distractibility

names?

21. Do you start doing one thing

2.26

2.94

7.89

$.008 * *$

Memory for names

at home and get distracted into

doing something else?

22. Do you find you can't quite

2.53

3.30

16.22

$.000 * * *$

Distractibility

remember something although it's

"on the tip of your tongue"?

23. Do you find you forget what

you came to the shops to buy?

24. Do you drop things?

1.42

2.34

13.68

$.001 * *$

Misdirected

actions

1.58

1.48

0.17

.675

Spatial/

kinaesthetic memory

25. Do you find you can't think of

2.29

1.80

2.74

.105

Distractibility anything to say?

Key: ${ }^{*} p<0.05 ; * * p<0.01 ; * * * p<0.001$. All remaining differences were non-significant. 
Table 2: Group mean ratings, standard deviations and $F$ value for each item of the

CFQ-for-others. Ratings of the frequency of occurrence of the different types of cognitive failures of the CFQ-for-others ranged from 0 (Never) to 4 (Very Often).

Significance levels are indicated prior to application of Bonferroni corrections. For corrected significance at the $p<0.05$ level, items must have a $p$-value of less than 0.005 .

\begin{tabular}{|c|c|c|c|c|}
\hline CFQ-for-others Item & Control & Dyslexic & $\mathbf{F}$ & $\mathbf{P}$ \\
\hline $\begin{array}{l}\text { 1. Absent-minded, that is making } \\
\text { mistakes in what he/she is doing } \\
\text { because he/she is thinking of } \\
\text { something else? }\end{array}$ & 1.52 & 2.24 & 9.98 & $.003 * *$ \\
\hline $\begin{array}{l}\text { 2. Finding it difficult to } \\
\text { concentrate on anything because } \\
\text { his/her attention tends to wander } \\
\text { from one thing to another? }\end{array}$ & 1.62 & 2.44 & 6.89 & $.012 * *$ \\
\hline $\begin{array}{l}\text { 3. Forgetful, such as forgetting } \\
\text { where he/she has put things, or } \\
\text { about appointments, or about what } \\
\text { he/she has done? }\end{array}$ & 1.95 & 2.40 & 1.60 & .213 \\
\hline $\begin{array}{l}\text { 4. Busy thinking about his/her own } \\
\text { affairs and not noticing what is } \\
\text { going on around him/her? }\end{array}$ & 2.00 & 1.96 & 0.02 & .897 \\
\hline $\begin{array}{l}\text { 5. Clumsy, for example, dropping } \\
\text { things or bumping into people? }\end{array}$ & 1.24 & 1.48 & 0.54 & .465 \\
\hline $\begin{array}{l}\text { 6. Having difficulty in making up } \\
\text { his/her mind? }\end{array}$ & 2.14 & 1.84 & 0.744 & .393 \\
\hline $\begin{array}{l}\text { 7. Disorganised, that is, getting } \\
\text { into a muddle when doing } \\
\text { something because of lack of } \\
\text { planning or concentration? }\end{array}$ & 1.05 & 2.20 & 12.136 & $.001 * *$ \\
\hline $\begin{array}{l}\text { 8. Getting unduly cross about } \\
\text { minor matters? }\end{array}$ & 1.76 & 2.04 & 0.55 & .463 \\
\hline
\end{tabular}

Key: ${ }^{*} p<0.05 ; * * p<0.01 ; * * * p<0.001$. All other differences were non-significant. 


\section{Footnotes.}

${ }^{1}$ As a further check, a random subsample of 4 participants was screened for dyslexia in the present study, using the ADI diagnostic measures. The standard WAIS-R subtests were employed to obtain a short form IQ, namely Similarities, Comprehension, Block Design, and Picture Completion (Wechsler, 1986a). This produced a mean of $110.75(\mathrm{SD}=4.19)$. All of the control group so screened obtained a spelling age of greater than 17 years (the ceiling on the WORD test is 17 years) and did not have any difficulties with the nonsense passage, either in terms of speed or accuracy of performance. 